\title{
O LUGAR DA PRÁXIS NA ANÁLISE DO DISCURSO
}

\author{
Rodrigo Oliveira Fonseca
}

\begin{abstract}
RESUMO: Dentre diferentes formas de conceber a práxis, há uma que poderá servir ao desenvolvimento de uma noção propriamente discursiva de práxis: anseio de sentido mal discernido que funciona como impulso à ação (SAMPAIO \& FREDERICO, 2006, p. 59). No entanto, haverá de se lidar antes com algumas questões caras à teoria do discurso, como a tese althusseriana (pascalina) do assujeitamento. Através da abordagem da práxis discursiva poderá se tornar mais clara a razão pela qual nenhuma formação discursiva simplesmente baixa em subjetividades inertes elou indiferentes, visto que ela é, por sua própria definição em Pêcheux, um modo de relacionar-se com a ideologia vigente, que se realiza através de um trabalho dos (e nos) sujeitos na história.
\end{abstract}

PALAVRAS-CHAVE: práxis - discurso - subjetivação

RESUMEN: Entre las diferentes formas de concebir a la praxis, hay una que podrá servir al desarrollo o de una idea adecuada de la praxis discursiva: el anhelo de sentido mal discernido que sirve como impulso para la acción (SAMPAIO \& FREDERICO, 2006, p. 59, en traducción libre del portugués). Sin embargo, antes habrá que lidiar con algunos problemas ejes a la teoría del discurso, como la tesis althusseriana (pascalina) de la sujeción. A través de la discusión de la praxis discursiva podrá ponerse más claro el porqué de una formación discursiva no simplemente bajar en subjetividades inertes e/o indiferentes, ya que por su propia definición en Pêcheux ella es una forma de relacionarse con la ideología dominante, que se lleva a cabo a través de un trabajo de los (y en los) sujetos en la historia.

PALABRAS-CLAVES: praxis - discurso - subjetivación

\section{APRESENTANDO A QUESTÃo}

Ainda e sempre, nós, os analistas do discurso, estamos, por concordância ideológica, às voltas com os nossos cavalos de troia, com as questões produtivas e (com)promissoras que o marxismo e que a psicanálise trazem de modo especial aos estudos da linguagem, em que importa abrir campos de questões e dar trabalho à linguística em seu próprio domínio - segundo a expressão de Michel PÊCHEUX ([1975] 1997).

A Análise do Discurso pecheutiana (doravante AD) opera com a convicção de que o fazer sentido tem a ver com os funcionamentos fonológicos, morfológicos e sintáticos, como tem a ver com os processos de enunciação. Ao mesmo tempo entende que sobre estes funcionamentos e processos instauram-se na interlocução pontos de deriva e de equivocidade, a partir dos quais determinados dizeres são tomados por dizeres outros (dizeres dos outros e do Outro), em processos de sustentação que podem

Universidade Federal do Rio Grande do Sul (UFRGS), doutorando em Estudos da Linguagem, mestre em História Social da Cultura (PUC-Rio), roflin@yahoo.com 
ser compreendidos mediante o levantamento de duas ordens de relações — relações de força e relações de sentido, condições de produção do sentido e filiação a formações discursivas. Busca pensar-se, assim, de modo aberto e articulado (dinâmico e estruturado), como a língua e a história afetam duas coerções: as que tocam a tomada da palavra e as que tocam os processos semânticos; a enunciação e a interpretação.

Esta singularidade no modo de compreender o fazer sentido é produzida pela presença consequente de saberes oriundos destas duas ciências da conflitividade moderna, o marxismo e a psicanálise. Ainda que ambas sofram constantes reapropriações produtoras de desvios de seus núcleos essencialmente políticos - o inconsciente, o desejo, a mais-valia, a luta de classes - e que (cf. HENRY, [1977]) elas tendam a não encontrar lugar no regaço da universidade, será sempre o caso de minimamente reconhecermos aquilo com o que se falta, quando faltamos com as suas questões: os impasses/inflexões das transformações históricas e aqueles da constituição dos sujeitos, as rupturas e os furos que social e pragmaticamente não cessamos de tentar suturar.

Se o marxismo é constitutivo da epistemologia da $\mathrm{AD}$, é o caso então de não desviar disso que bem sabemos, que faz sentido, mas que não dizemos ou dizemos pouco diante de tudo o que implica: "a linguagem é uma prática; não [apenas] no sentido de efetuar atos mas porque pratica sentidos, intervém no real. Essa é a maneira mais forte de compreender a práxis simbólica" (ORLANDI, 2001, p. 95). Esse lugar das práticas, para não ser tomado de modo funcional, circular, fechado ou estruturalista, pode e deve ser compreendido como lugar essencial de trabalho, de produção cotidiana e de ritual do novo no interior do mesmo, do que tende a superação e a falhas, lugar de desentendimentos e de uma série de choques que questionam e redefinem constantemente as suas fronteiras.

Língua e história representam uma relação essencial na experiência humana, mas não se fecham nem se recobrem. Por isso sempre se diz mais/menos/diferente do que se vive. E vice-versa. Nesse lugar contraditório de determinação dos sentidos dos objetos (e) da experiência humana, lugar ao mesmo tempo material e social, cabe pensar o que exatamente move a língua em sua inscrição na história. Aí localizamos o problema da práxis.

\section{MAS QUE PRÁXIS?}

Dentre diferentes formas de conceber a práxis, há uma que pode servir de modo satisfatório ao desenvolvimento de uma noção propriamente discursiva de práxis: anseio de sentido mal discernido que funciona como impulso à ação (SAMPAIO \& FREDERICO, 2006, p. 59). Esse anseio tem relação com a falta e com o excesso de todo dizer, com o batimento sempre renovado entre os já-ditos e o a-dizer a respeito de alguma coisa (ORLANDI, 2007), com a incompletude constitutiva de todo dizer historicamente tomado: significante de experiências recortadas, disputadas, esquecidas e/ou articuladas, em uma pulsação incessante que vai e volta entre o sem-sentido e o já- 
sentido, com o assédio constante do non sens e de um já-sentido insistente e (in)desejado dos outros e do Outro. Por aí podemos compreender melhor o fato de que não falamos (apenas) palavras, nem falamos (exatamente) seus conteúdos. Falamos com palavras (ibid., p. 15). O dizer nos serve - na ambivalência desse e de todo dizer. Ou seja: ele nos serve de bandeja e na bandeja.

Trabalhar essa perspectiva de práxis implica em problematizar a noção de funcionamento, tributária do estruturalismo saussuriano e muito trabalhada em $\mathrm{AD}$, e que carrega consigo um elemento estranho à tradição teórica aberta por Marx e Engels, sobretudo se abusivamente estendida na forma de "funcionamentos sociais". A noção de funcionamento representa um salto de grandes proporções nos estudos da linguagem, ocupando o lugar daquilo que antes da linguística apontava para a função da linguagem (enquanto expressão e exteriorização do pensamento). Com Saussure o foco se desloca para os funcionamentos significantes, para aquilo que a língua faz e que a faz, a sua ordem significante. As consequências negativas são apontadas por todos os linguistas que depois retornaram ao corte língua-fala para problematizá-lo em favor de uma maior complexidade na relação entre sistema e liberdade e da compreensão do lugar dos homens e da história em seu interior.

É possível que a centralidade da noção de funcionamento no pensamento linguístico da $\mathrm{AD}$ explique-se pelo modo como se deu a filiação teórica ao materialismo histórico e pela manutenção da linguística no papel de ciência piloto. Tal como - no marxismo - as ideias têm sua autonomia contestada frente à práxis social, também os processos de significação foram tomados enquanto dependentes de uma base material e não transparente: a língua. No entanto, se o caráter objetivo da língua para Saussure é assegurado pela arbitrariedade do sistema (ou externalidade em relação aos referentes do mundo), para Marx toda objetividade deve ser apreendida enquanto atividade humana sensível, enquanto práxis social, objetivação - conforme a $1^{\mathrm{a}}$ tese sobre Feuerbach, onde Marx também critica o materialismo vulgar, que não considera a atividade humana enquanto atividade objetiva (MARX, [1846] 1993, p. 11), sendo esta a base para que depois se buscasse pensar as sistematicidades da fala, das práticas linguageiras. Nessa direção, para PÊCHEUX \& FUCHS ([1975], p. 227) há de se trabalhar com "a tese materialista segundo a qual os 'objetos' não são invariantes primeiros, mas pontos de estabilização de processos".

Temos aí a impossibilidade de se tomar, em perspectiva marxista, a fala (e o discurso) como índice da liberdade humana em oposição ao caráter sistêmico da língua. Nada do humano ou do histórico pode ser tomado como uma abstração ideal sobre a liberdade (sem limites e mediações) ou a sistematicidade (sem falhas e materialidade), sob o risco de ignorarmos as contingências e contradições concretas e cedermos a fraseologias ideológicas grosseiras. Se falamos (e como!), não é apesar das regras da língua. Pelo contrário, é nelas que falamos, é por sermos capazes de (nos) jogarmos nelas e com elas. "A sintaxe é a base da criatividade histórica" (GADET, [1991] 2011,

\footnotetext{
${ }^{1}$ Que enquanto dicotomia, para Courtine (Análise do discurso político: o discurso comunista endereçado aos cristãos. São Paulo: EdUFSCar, [1981] 2009), obstaculizaria própria a constituição da AD.
} 
p. 102). O mesmo vale para o poder: não vivemos apesar dos poderes, vivemos (e lutamos) por eles ${ }^{2}$.

Como a práxis não deve ser pensada à margem do político e da luta de classes (afinal, não se pode fazer tudo, e certas coisas são impossíveis de não serem feitas em sociedade), também a língua não deve ser pensada livre da alíngua (Milner apud PÊCHEUX \& GADET, ([1981] 2004, p. 52), apenas enquanto estrutura de funcionamentos ou sistema de diferenças, sob o risco de se cair em formalismo ou em funcionalismo - de modo a "entregar o ouro ao bandido", não contestando a brecha que se deixa para que a região da semântica possa ficar sob o domínio dos estudos empiristas ou de uma "semântica geral". Não se pode jamais dizer tudo, como é impossível não dizer de determinada maneira, e isso que falta e que excede é mesmo a razão de haver língua, é o que a move e constitui enquanto sistema, e está fora dela, é não-língua. Sendo estrutura de base (dos processos discursivos), eixo que lhe confere sistematicidade, é também uma dinâmica, uma forma de movência e significação em meio a - e para - totalidades contraditórias (complexas) em permanente processo de reprodução e transformação. Por isso dizemos que a língua não preexiste ao discurso, tal como os meios de produzir de uma sociedade não preexistem aos produtos, sendo também eles produzidos e constantemente transformados.

Deve ficar claro que por práxis não tomamos a consciência que os sujeitos possam ter de suas ações, visto que a práxis é sempre "anterior à razão refletida e ao reconhecimento de quem a executa" (SAMPAIO \& FREDERICO, 2006, p. 59), na medida em que o ser antecede e extrapola toda consciência possível. Como diz João Bernardo,

\begin{abstract}
Marx procedeu a uma transformação profunda na concepção de "ação", de conseqüências ideológicas sem precedentes. A ação deixou de ser pensada como um processo intelectual e, pelo menos no seu momento inicial, interior ao eu e, de qualquer modo, inteiramente redutível ao modelo do eu. Marx passou a conceber a ação como práxis, ou seja, como uma prática simultaneamente material e social. (...) a redução da ação a processos mentais baseia-se na escamoteação da ação enquanto processo prático de produção material. (BERNARDO, [1991] 2009, p. 73)
\end{abstract}

Diferente da ideologia tal como concebida por Althusser, a práxis não é ou pelo menos não se encerra em uma voz-ordem-mandamento que nos interpela enquanto sujeitos, fazendo com que assim venhamos a ocupar um (outro) lugar previamente estabelecido. Se ela é uma espécie de (em) razão da vida que precede e extrapola a racionalização, e que nos ajuda a pensar a ação humana em sua base material e social, então nos parece válido voltar ao próprio conceito de ideologia. Devemos reter o gesto althusseriano de retirar ou expandir as ideologias tanto do mundo das ideias/visão de mundo quanto das formas (distorcidas) de expressão da base econômica - afinal, não as encontramos nem tanto ao céu nem tanto à terra -, percebendo porém que por meio das

\footnotetext{
${ }^{2}$ Não seria mesmo característico do idealismo em suas variações esconder as suas armas ou fingir que não as têm ou não as usa?
} 
ideologias incidem sobre as nossas práticas tanto as pressões reprodutivas quanto as de transformação ${ }^{3}$, tanto o apagamento imaginário das condições reais de existência quanto o desejo de eliminação destas condições, de dissolução deste lugar previamente ocupado e administrado. As ideologias atuariam assim tanto pelo fazer ver da ordem (que não se encerra em reproduzir o desconhecimento das causas) quanto pelo fazer ver de uma nova partilha do sensível (RANCIÈRE, 1996) inscrita nas fraturas e fragmentações dessa ordem. As ideologias, nessa perspectiva, representariam as pressões da história sobre a práxis, a forma como somos arremessados e nos arremessamos em nosso tempo - nunca apenas para perpetuá-lo.

\section{SUPERAÇÃO DO ESTRUTURALISMO E RENOVAÇÃO DAS AMBIÇÕES}

Haverá assim de se lidar antes com algumas questões da teoria do discurso, sobretudo numa tentativa de pensar o papel dos estudos históricos e seu levantamento das relações sociais no conjunto dos procedimentos de análise - mais especificamente, na consideração das condições de produção dos discursos para além da montagem do corpus. Entendo que as relações sociais (as assimetrias, as relações de força) presidem a tomada da palavra, a enunciação dos sujeitos na história, em especial quando se trata, como nos casos em que analiso, de interditar temas e sujeitos indesejados. Busco procedimentos que nos permitam chegar além do mapeamento de efeitos de sentido e dos efeitos-sujeito, atentando para os modos de subjetivação no interior das conjunturas, como mais adiante será exposto.

A influência do filósofo marxista Louis Althusser na constituição da teoria pecheutiana do discurso é insofismável. Foi o mestre de Michel Pêcheux que promoveu uma forma de pensar a ideologia enquanto prática ritual produtora de evidências subjetivas e semânticas, como também foi Althusser que despertou um interesse inaudito pelas teses lacanianas no interior do marxismo. Isso após anos e anos em que o freudismo aparecia aqui e ali como simples perversão burguesa ou ideologia reacionária e mistificadora. Hoje, podemos, mais tranquilamente (e com alguma malícia) carimbar: que belo recalque!

Pêcheux e o grupo de pesquisadores reunidos em torno das propostas da $\mathrm{AD}$, no entanto, trilhamos esse caminho aberto por Althusser de modo a superá-lo dialeticamente naquilo que implicava em teoricismos. É o real da língua, da história e dos sujeitos, perseguido nos trabalhos de análise, que merece os "créditos" nessa superação. $\mathrm{O}$ que aparentemente funcionava bem demais na perseguição dos mitos da ideologia dominante, seu poder unificador e homogeneizante por detrás das superfícies, acabou transformando-se em um conjunto amplo e heterodoxo de questões e

\footnotetext{
${ }^{3}$ Pêcheux, em texto que tivemos acesso recentemente (Ideologia - aprisionamento ou campo paradoxal?, [1982] 2011, p 115), explica que por reprodução Louis Althusser jamais se referiu a repetição do mesmo. Althusser teria buscado "dar continuidade a determinadas colocações de Gramsci a respeito do conceito de hegemonia e da proximidade invisível do Estado no cotidiano", devendo-se considerar que os processos de reprodução ideológica também são locais de resistência múltipla.
} 
procedimentos acerca da existência das condições verbais contraditórias de um discurso, das formas de jogo e resistência nas lutas ideológicas. Uma maior compreensão da materialidade da língua, de seu funcionamento equívoco (PÊCHEUX \& GADET, [1981] 2004), pode assim ajudar a irmos além da simples consideração quanto à "autonomia relativa das instâncias", introduzindo atravessamentos constitutivos entre língua e história, que as deslocam e as recompõe em seus papéis diretivos nos estudos do discurso, e introduzindo elementos desestabilizadores à teoria althusseriana (pascalina) do assujeitamento, ainda que nos deparemos em nossas investigações com os bons e os maus sujeitos. Além dos bons e dos maus vale pensar também nos feios (segundo proposta de BECK, 2011 para a nomeação da $3^{\mathrm{a}}$ modalidade pecheutiana de tomada de posição subjetiva no campo das dominâncias discursivas), aqueles que desestabilizam a régua normativa, ou, simplesmente, aqueles que trazem com a sua desidentidade característica a necessidade de uma postura mais aberta por parte do pesquisador dos discursos.

Quanto às superações das influências estruturalistas e teoricistas sobre a $\mathrm{AD}$, do lado da psicanálise, PÊCHEUX ([1978] 1997) mostra que houve uma sobreposição entre as categorias de sujeito e Eu/Ego. Foi ela a que fez resvalar para a ideia da identificação plena do sujeito com os lugares sociais (à moda funcionalista) e para o poder unificador da consciência, retirando-a do aparelho psíquico, livrando-a das pressões do desejo inconsciente - e mesmo das pressões do Super-Eu, se as entendemos enquanto solicitações impossíveis.

Também pelo lado do marxismo - ou em especial deste lado - o teoricismo althusseriano demonstrou grandes limitações em sua tentativa de refazer um caminho para a obra de Marx sem passar por Hegel (como ele próprio esclarece em ALTHUSSER, [1972] 1978). Sem passar por Hegel ou, o que é mais grave, recalcando esta passagem, material e indelevelmente inscrita no marxismo, e sem a qual ficam comprometidas sua lógica dialética da contradição, suas mediações concretas e a própria forma de compreender a processualidade histórica fora de um determinismo que, "em última instância", entrega todo o papel dinâmico à reprodução social ${ }^{4}$.

Jean-Jacques Courtine, com grande sagacidade, manifestou-se sobre algumas dessas limitações, expressando o diferencial implicado na análise por meio de um trabalho efetivo com a categoria da contradição. Escreveu ele:

\begin{abstract}
O tema da contradição atravessa dessa forma nossa pesquisa em diferentes níveis, de maneira recorrente, com insistência; desejamos que produza um efeito de conhecimento, que seja um testemunho da presença do marxismo como corpo teórico real e não como uma expressão não significativa. (COURTINE, 1981, p. 12. Tradução livre)
\end{abstract}

A tripla presença do marxismo, da psicanálise e da linguística na $\mathrm{AD}$, com todas as dificuldades que advêm desse encontro, deve ser realmente significatica, consequente e profícua. Além do reconhecimento de sua presença na constituição epistemológica da

\footnotetext{
${ }^{4}$ Ponto este que merece ser repensado a partir do esclarecimento feito na nota anterior, pelo qual reproduzir não é apenas repetir ou conservar.
} 
teoria do discurso, devemos ser desafiados a mostrar em nossas análises a sua contribuição para a produção de conhecimento.

E aí também temos outro diferencial da $\mathrm{AD}$, que resiste e enfrenta certos princípios do pós-modernismo e do multiculturalismo, obstrutores dos processos de conhecimento científico: a AD efetivamente ambiciona produzir conhecimento, de modo explícito e crítico; ela não quer ser um golpe de força acadêmico, pondo leitura sobre leitura, versão sobre versão, como se o fato de uma leitura poder ser outra implicasse em dizer que ela pode ser qualquer. Com margens, nem soltos nem cristalizados, os sentidos são historicamente determinados e socialmente administrados, e quanto a isso a $\mathrm{AD}$ não pretende lançar sobre os textos e as interpretações nem um olhar (sabido) de ordem técnica-semiótica, sobre as superfícies textuais, nem um outro olhar (mais sabido ainda) de ordem erudita-hermenêutica, sobre os conteúdos.

Para além de todas as contribuições das nossas disciplinas irmãs (e elas são muitas, como as ambivalências e os desentendimentos aí produzidos), há de se ter clareza do motor de nossas análises: se os efeitos de sentido são como produtos de um rico processo social e linguageiro tendencialmente apagado, então, para compreender como se interpreta, muito mais do que se reinterpretar em nova grade, há de se jogar luz sobre esse processo histórico-discursivo, superando as ordens de evidência, circularidade e cristalização de seus produtos.

Para seguir fazendo da $\mathrm{AD}$ um conjunto de princípios e procedimentos afeitos a essa ambição de conhecimento, para fazer com que juntamente ao seu crescimento e difusão institucional não se instaurem esquecimentos fragilizadores e adaptações suicidas, temos diante de nós todo um trabalho de retificações e sobretudo de superação. Mas como diria Althusser, este é um trabalho sem fim.

Sendo impossível (e até desonesto) negar as contribuições da leitura althusseriana do marxismo, considero porém, que o silêncio ou silenciamento referente a categorias como trabalho e práxis não apenas comprometem o alcance da $\mathrm{AD}$, como desarmam toda a "periculosidade" do materialismo histórico, restringindo suas "problemáticas" à consideração de um novo continente científico e seu corte epistemológico. Produz princípios que nem sempre reverberam em procedimentos.

\section{UM PROGRAMA DE RE-LEITURAS}

Viemos trabalhando em uma proposta conceitual de práxis discursiva, partindo de algumas considerações de Michel Pêcheux, tais como aquelas referentes às três modalidades de tomada de posição (PÊCHEUX, [1975] 1997), à agitação nas filiações do sentido (id., [1983] 1997), e, sobretudo, ao deslocamento tendencial do sujeito enunciador (id., 1981).

Outras referências fundamentais (e a nosso ver complementares neste empreendimento) consistem na proposta do trio MALDIDIER, NORMAND e ROBIN ([1976] 1994) para um enfoque discursivo da enunciação - apontado como uma grave lacuna por Pêcheux e Catherine Fuchs em 1975. Também discuto a forma particular e 
radicalmente historicizante como Jacques RANCIÈRE (1996) entende os processos de subjetivação:

\author{
(...) produção, por uma série de atos, de uma instância e de uma capacidade \\ de enunciação que não eram identificáveis num campo de experiência dado, \\ cuja identificação caminha a par com uma reconfiguração do campo de \\ experiência. (ibid., 47)
}

Não há discurso (verbal) sem enunciação. Esse fator aparentemente simples deve implicar em uma compreensão mais fina da relação dos sujeitos históricos com os seus dizeres, do que lhes faz dobrar, morder ou queimar a língua, assim como pressão daquela dor prévia, que como a ânsia de um sentido mal discernido, faz com que a língua se agite. Se Lenin (apud PÊCHEUX, [1975] 1997) acerta ao dizer que a língua vai onde o dente dói, pode-se complementar dizendo que nem sempre o que ela faz é levar alento.

Tem sido desafiador e produtivo nas investigações, sobretudo em meio aos procedimentos de de-sintagmatização (ou deslinearização) discursiva, trazer o campo de experiência dos sujeitos históricos, campo social este que não deve ser visto como um pano de fundo ou uma moldura dentro da qual se dão suas ações. Este campo constantemente sofre reconfigurações por parte dos sujeitos em sua práxis e intervém no fazer sentido. Contra a frágil ou ideal relação frente-fundo que domina a compreensão do que se chama "situações de comunicação", entra em questão o trabalho sempre incompleto dos sujeitos históricos na construção dos seus palanques, de onde eles podem falar fazendo-se visíveis e audíveis. Estes palanques são a instância e a capacidade dinâmica que condicionam as práticas discursivas dos sujeitos históricos, em meio às relações de força e às formas de combate pelo sentido nas quais os discursos ecoam ou não.

Entendo que pela conceituação da práxis discursiva, se conseguirmos atestar sua contribuição para o conhecimento efetivo dos processos discursivos, poderemos superar dois pontos frágeis ou no mínimo produtores de leituras indesejadas da teoria do discurso, os quais são explorados por seus críticos externos: 1) o assujeitamento sem resistência aos já ditos; e 2) a resistência como fator exclusivamente imanente, acidental, inconsciente e pontual.

Não se trata de "regredir" a uma posição que jogue fora as pesquisas e as descobertas da psicanálise em relação ao inconsciente, como seria no caso de concebermos os processos de subjetivação de modo centrado, completo, interior (sem exterior). Tudo isso implicaria na consideração de sujeitos a-históricos, não determinados e indiferentes. O que é preciso dizer é que a concepção althusseriana da interpelação dos indivíduos em sujeitos pela ideologia - concepção pascalina, como ALTHUSSER ([1970] 1985) reconhece - é muito mais sociológica que histórica: "ajoelhai-vos, orai e acreditareis", primeiro a prática ritual, circular, depois o convencimento íntimo, facilitador. Sofre-se aqui uma tentação de estaticidade, embotando-se os processos e pontos de transformação no interior da reprodução, os choques, desmaios, rachaduras, desentendimentos,... E por aí derivamos quanto às 
tentações de controle dos fenômenos por parte do pesquisador: a exterioridade vista como Peste, o inferno são os outros... A ilusão da consciência e a objetividade das representações... Os vivos, cada vez mais governados pelos mortos... ao gosto do pai do positivismo filosófico, Comte.

Por esta via se deixa escapar a consideração essencial de que as ideologias são formas de exercício de uma luta (RANCIÈRE, [1969] 1971), formas pelas quais os homens adquirem consciência de seus conflitos e os levam até o fim (MARX, [1859] 2008). Deixa-se também de perceber que a ideologia dominante e seus sujeitos não podem trabalhar completamente cegos e obtusos em prol da reprodução social; também aí o que há é sempre uma luta, pois que só há dominação frente às e em função das resistências e enfrentamentos ${ }^{5}$.

Por meio da práxis discursiva poderá se tornar mais clara a razão pela qual nenhuma formação discursiva simplesmente baixa em subjetividades inertes e/ou indiferentes: toda formação discursiva é um modo de relacionar-se com a ideologia vigente, modo este que se realiza através de um trabalho dos sujeitos na história. Até mesmo para sermos dominados, explorados e alienados temos que trabalhar - muitas vezes é exatamente para isso que temos de trabalhar; muitas vezes é apenas para isso que trabalhamos.

A nosso ver, Michel PÊCHEUX ([1975] 1997, p. 160) sintetiza este processo de um modo bastante esclarecedor: "as palavras, expressões, proposições, etc., mudam de sentido segundo as posições sustentadas por aqueles que as empregam". Ou seja, a discursividade não se restringe ao sofrimento dos efeitos ideológicos por "se usar" uma palavra, expressão, proposição, etc., nem ao encontro fortuito com aquilo que elas podem dizer pelo Outro, no jogo das não-coincidências do dizer (segundo a rica proposta de AUTHIER-REVUZ, 1998). A discursividade se realiza através de todo o trabalho (histórico-subjetivo) advindo da sustentação de uma posição - trabalho do qual nem sempre colhemos os frutos, e que tendemos a ignorar (a apagar ou recalcar) o seu caráter de produção social.

Entendo, por fim, que os sujeitos históricos também são levados a ponto de jogar com a língua, as palavras e suas formulações, desenvolvendo uma práxis discursiva, uma esquivocidade, que os permite lidar com a "forma material concreta sob as quais as ‘ideias' entram em luta na história” (PÊCHEUX, [1977] 1980), e que faz com que o discurso seja efetivamente um instrumento fundamental da prática política, mesmo quando deixamos de dizer algo - ou exatamente por isso.

\footnotetext{
${ }^{5}$ Tentei mostrar isso em FONSECA, Rodrigo Oliveira. Os malabarismos da imprensa com o discurso de Lula. Observatório da Imprensa. São Paulo, v. 13, n. 505, setembro de 2008. Disponível em www.observatoriodaimprensa.com.br Acesso em: 01 out. 2011.
} 


\section{REFERÊNCIAS}

ALTHUSSER, Louis. [1970] Aparelhos Ideológicos de Estado: nota sobre os aparelhos ideológicos de Estado (AIE). $2^{\text {a }}$ edição. Tradução de Walter José Evangelista e Maria Laura Viveiros de Castro. Rio de Janeiro: Gral, 1985.

[1972] Posições - I. Tradução de Walter José Evangelista. Rio de Janeiro: Graal, 1978.

AUTHIER-REVUZ, Jacqueline. Palavras incertas. As não-coincidências do dizer. Tradução de Cláudia Pfeiffer et al. Campinas: Ed da Unicamp, 1998.

BECK, Maurício. Aurora Mexicana - processos de resistência-revolta-revolução em lutas populares da América Latina: o exemplo do discurso zapatista. 2010. 179f. Tese (doutorado em Letras) - Instituto de Letras, UFSM, Santa Maria, RS.

BERNARDO, João. [1991] Economia dos Conflitos Sociais. $2^{\mathrm{a}}$ edição. São Paulo: Expressão Popular, 2009.

COURTINE, Jean-Jacques. "Análisis del discurso político (el discurso comunista dirigido a los cristianos)". Tradução para o espanhol de Maria del Carmen SaintPierre. In: Langages, junho de 1981.

[1981] Análise do discurso político: o discurso comunista endereçado aos cristãos. Tradução de Birck et al. São Paulo: EdUFSCar, 2009.

GADET, Françoise. [1991] A língua inatingível (entrevista ao Canadian Journal of Political and Social Theory). Tradução de Sérgio Freire. In: PÊCHEUX, Michel. Análise de Discurso: Michel Pêcheux - textos selecionados por Eni Orlandi. $2^{\text {a }}$ edição. Campinas, SP: Pontes, 2011, p. 93-105.

HENRY, Paul. [1977] A ferramenta imperfeita: língua, sujeito e discurso. Tradução de $M^{\text {a }}$ Fausta P. de Castro. Campinas, SP: Editora da UNICAMP, 1992.

INDURSKY, Freda. "Unicidade, Desdobramento, Fragmentação: trajetória da noção de sujeito em análise do discurso" in MITTMANN, Solange, GRIGOLETTO, Evandra \& CAZARIN, Ercília (org.), Práticas discursivas e identitárias: sujeito e língua. Porto Alegre: Nova Prova, 2008, p. 9-33.

EAGLETON, Terry. Ideologia - uma introdução. São Paulo: Editora da Universidade Estadual Paulista: Editora Boitempo, 1997.

MALDIDIER, D. NORMAND, Cl. e ROBIN, R. [1976] "Discurso e ideologia: bases para uma pesquisa" in ORLANDI, Eni P. (org.), Gestos de leitura: da história no discurso. Campinas, SP: Editora da Unicamp, 1994.

MARX, Karl. [1846] Teses sobre Feuerbach. In: MARX, Karl \& ENGELS, Friedrich. $A$ Ideologia Alemã (Feuerbach). Tradução de José Carlos Bruni e Marco Aurélio Nogueira. $9^{a}$ edição. São Paulo: Hucitec, 1993, p. 11-14.

. [1859] Contribuição à crítica da economia política. Tradução de Florestan Fernandes. $2^{a}$ edição. São Paulo: Editora Expressão Popular: 2008.

ORLANDI, Eni. Análise de Discurso: princípios e procedimentos. $3^{\mathrm{a}}$ edição. Campinas, SP: Pontes, 2001.

. As formas do silêncio no movimento dos sentidos. $6^{\mathrm{a}}$ edição. Campinas, SP: Editora da Unicamp, 2007. 
PÊCHEUX, Michel. [1975] Semântica e discurso: uma crítica à afirmação do óbvio. Tradução de Eni Orlandi et al. $3^{\mathrm{a}}$ edição. Campinas, SP: Editora da Unicamp, 1997.

[1977] "Remontemos de Foucault a Spinoza". In: TOLEDO, Monforte (org). El discurso político. México: Nueva Imagen, 1980, p. 181-200. Trad. GREGOLIN, Maria do Rosário. Xerox.

. [1978] "Só há causa daquilo que falha ou o inverno político francês: início de uma retificação". in Semântica e Discurso: uma crítica à afirmação do óbvio. Campinas, SP: Ed. da Unicamp, 1997.

. [1981] Ouverture du Colloque. In: Colloque Matérialités Discursives, Lille: Presses Universitaire de Lille, v. 1, p. 6-10.

. [1982] Ideologia - aprisionamento ou campo paradoxal? Tradução de Carmen Zink. In: PÊCHEUX, M.. Análise de Discurso: Michel Pêcheux - textos selecionados por Eni Orlandi. 2a edição. Campinas, SP: Pontes, 2011, p. 107119.

[1983] O discurso: estrutura ou acontecimento. Tradução de Eni Orlandi. $2^{\mathrm{a}}$ edição. Campinas, SP: Pontes, 1997.

PÊCHEUX, Michel \& FUCHS, Catherine. [1975] A propósito da análise automática do discurso: atualização e perspectivas. Trad. Péricles Cunha. In: GADET, F. \& HAK, T. (org). Por uma análise automática do discurso: uma introdução à obra de Michel Pêcheux. $3^{a}$ edição. Campinas, SP: Editora da Unicamp, 1997, pp. 163-252.

PÊCHEUX, M. \& GADET, F. [1981] A língua inatingível. Tradução de Bethania Mariani. Campinas, SP: Pontes, 2004.

RANCIÈRE, Jacques. [1969] Sobre a teoria da ideologia: a política de Althusser. Tradução não referida. Porto: Portucalense, 1971.

O desentendimento: política e filosofia. Tradução de Ângela Leite Lopes. São Paulo: Editora 34, 1996.

SAMPAIO, Benedito Arthur \& FREDERICO, Celso. Dialética e materialismo: Marx entre Hegel e Feuerbach. Rio de Janeiro: Editora UFRJ, 2006. 